\title{
Genotoxicity of quinolones: Substituents contribution and transformation products QSAR evaluation using 2D and 3D models
}

\author{
Min $\mathrm{Li}^{\mathrm{a}, \mathrm{b}}$, Dongbin Wei ${ }^{\mathrm{a}, *}$, Huimin Zhao ${ }^{\mathrm{a}}$, Yuguo Du ${ }^{\mathrm{a}, \mathrm{b}, *}$ \\ a State Key Laboratory of Environmental Chemistry and Ecotoxicology, Research Center for Eco-Environmental Sciences, Chinese Academy of Sciences, Beijing 100085, PR China \\ ${ }^{\mathrm{b}}$ University of Chinese Academy of Sciences, Beijing 100049, PR China
}

\section{H I G H L I G H T S}

- Genotoxicity of 21 quinolones was determined and analyzed with QSAR method.

- Big size and/or positive charge at 1-position substituent increase genotoxicity.

- Small size and/or negative charge at 8-position substituent increase genotoxicity.

- Negative charge at 7-position substituent increase genotoxicity.

- QSAR model showed that most metabolites had higher genotoxicity than precursor.

\section{A R T I C L E I N F O}

\section{Article history:}

Received 7 March 2013

Received in revised form 26 August 2013

Accepted 1 September 2013

Available online 27 September 2013

\section{Keywords:}

Quinolone

Genotoxicity

QSAR

COMFA

\begin{abstract}
A B S T R A C T
The genotoxicity of 21 quinolones antibiotics was determined using SOS/umu assay. Some quinolones exhibited high genotoxicity, and the chemical substituent on quinolone ring significantly affected genotoxicity. To establish the relationship between genotoxicity and substituent, a 2D-QSAR model based on quantum chemical parameters was developed. Calculation suggested that both steric and electrostatic properties were correlated well with genotoxicity. Furthermore, the specific effect on three key active sites (1-, 7- and 8-positions) of quinolone ring was investigated using a 3D-QSAR (comparative molecular field analysis, CoMFA) method. From our modeling, the genotoxicity increased when substituents had: (1) big volume and/or positive charge at 1-position; (2) negative charge at 7-position; and (3) small volume and/or negative charge at 8-position. The developed QSAR models were applicable to estimate genotoxicity of quinolones antibiotics and their transformation products. It is noted that some of the transformation products exhibited higher genotoxicity comparing to their precursor (e.g., ciprofloxacin). This study provided an alternative way to understand the molecule genotoxicity of quinolones derivatives, as well as to evaluate their potential environmental risks.
\end{abstract}

(c) 2013 Elsevier Ltd. All rights reserved.

\section{Introduction}

Quinolones, the most important antibacterial antibiotics with broad-spectrum activity and non-cross tolerance, have been widely used for the clinical treatment of human and veterinary diseases. The pharmacological mechanism was proposed that the quinolones could block bacteria DNA replication by inhibiting the bacterial DNA-gyrase and topoisomerase IV (Bryan et al., 1989; Hooper, 2001). Unfortunately, due to the excessive addition in the feed, these drugs have also been frequently detected in

\footnotetext{
* Corresponding authors. Address: State Key Laboratory of Environmental Chemistry and Ecotoxicology, Research Center for Eco-Environmental Sciences, Chinese Academy of Sciences, Beijing 100085, PR China. Tel.: +86 1062849441 ; fax: +861062923563 (D. Wei), tel.: +8610 62849126; fax: +86 1062923563 (Y. Du).

E-mail addresses: bkdlimin@126.com (M. Li), weidb@rcees.ac.cn (D. Wei), wyuchemys10zhm@126.com (H. Zhao), duyuguo@rcees.ac.cn (Y. Du).
}

environmental samples ascribing to the excretion via urine or feces. The concentration of ofloxacin in surface water bodies has been reported at $0.05 \mu \mathrm{g} / \mathrm{L}$ (Golet et al., 2002; Tong et al., 2011), and ciprofloxacin could reach as high as $5.93 \mu \mathrm{g} / \mathrm{L}$ for rivers contaminated by animal-farm effluents (Wei et al., 2012). In raw sewages and the secondary effluents from sewage treatment plants, 10 quinolones antibiotics were found and the concentrations ranged from 0.1 to $2.6 \mu \mathrm{g} / \mathrm{L}$ and 0.05 to $1.0 \mu \mathrm{g} / \mathrm{L}$, respectively (Tong et al., 2011; Jia et al., 2012). It is worth noting that ciprofloxacin have also been detected in untreated hospital sewages at a level of $101 \mu \mathrm{g} / \mathrm{L}$ (Lindberg et al., 2004; Martins et al., 2008).

The persistent residue of quinolones in aquatic system could lead to serious threat to ecosystem and human health. It was reported that the cyanobacterium (Microcystis aeruginosa) and duckweed (Lemna minor) were quite sensitive to fluoroquinolones, the median effective concentrations $\left(\mathrm{EC}_{50}\right)$ of levofloxacin for 5 -d 
growth reproduction of $M$. aeruginosa and 7-d reproduction of $L$. minor were 7.9 and $51 \mu \mathrm{g} / \mathrm{L}$, respectively (Robinson et al., 2005; Ebert et al., 2011). Most of quinolones exhibited mutagenicity to bacteria (Mamber et al., 1993), and a large proportion of hospital sewages containing quinolone-like antibiotics induced bacterial genotoxicity (Hartmann et al., 1998). In addition, it was reported that more than $70 \%$ of bacteria had become insensitive against at least one antibiotic and exhibited multiple resistance patterns (Hirsch et al., 1999), and the antibiotic resistance of bacteria has become a serious issue.

More than 10000 of quinolones compounds have been patented up to date (Andersson and Mac Gowan, 2003) and dozens of them are prevalent in application. It is impossible to evaluate the biological toxicities and potential ecological risks of all quinolones concerning the cost-effective analysis. Alternatively, quantitative structure-activity relationship (QSAR) technique is established to solve this problem in pharmacology, toxicology and environmental science (Blum and Speece, 1990). In the last decades, QSAR method has already been applied in the field of molecular design, as well as antibacterial activity and toxicity evaluation of quinolones (Ohta and Koga, 1991; Lee et al., 1996; Llorente et al., 1996; Minovski et al., 2011). Genotoxicity is one of the primary adverse effects of quinolones antibiotics limiting its further application (Domagala, 1994). Hu et al. (2007) attributed the genotoxicity to the hydrophobicity and electron transfer from quinolones molecules to DNA or protein molecules. However, the relationship between substituent on quinolone ring and the whole molecular genotoxicity is still unknown. In addition, some reports showed that toxicity had significant elevation in quinolones photolysis process ( $\mathrm{Li}$ et al., 2011) and some other processes. Moreover, many metabolite analyses revealed that the quinolone skeleton remained intact (Wetzstein et al., 1999; Dodd et al., 2005; De Witte et al., 2009; Ge et al., 2010; Li et al., 2011) in most transformation products. So it is necessary to consider the toxicity of not only quinolone precursors but also their transformation products.

In this study, the SOS/umu genotoxicity assay has been used to measure the adverse biological effect of 21 quinolones antibiotics. The respective contribution of each key substituent towards the genotoxicity of quinolones was illuminated combining the quantum chemical descriptors in 2D-QSAR model and molecular field information in 3D-QSAR model. More importantly, the developed 3D-QSAR model was applied to estimate the genotoxicity of quinolone antibiotics and their transformation products. The current study provided a feasible method to predict the potential environmental risks for quinolone analogs using QSAR technique.

\section{Experimental sections}

\subsection{Reagents and chemicals}

The structures of the 21 tested quinolone antibiotics are shown in Table 1a. Cinoxacin (CIN), ciprofloxacin (CIP), danofloxacin (DAN), difloxacin hydrochloride (DIF), enoxacin (ENO), enrofloxacin (ENR), fleroxacin (FLE), levofloxacin (LEV), lomefloxacin hydrochloride (LOM), moxifloxacin hydrochloride (MOX), norfloxacin (NOR), ofloxacin (OFL), pazufloxacin (PAZ), pipemidic acid (PIP), sparfloxacin hydrochloride (SAR) and sparfloxacin (SPA) were purchased from Sigma-Aldrich as HPLC or analytical reagent $(>98 \%$ purity). Balofloxacin (BAL), gatifloxacin (GAT), nadifloxacin (NAD) and pefloxacin (PEF) were obtained from the National Institutes for Food and Drug Control of China (at least 97\% purity). Rufloxacin hydrochloride (RUF) with 99\% purity was obtained from International Laboratory (US). All reagents were used directly without further purification. The stock solutions of all studied compounds were prepared in ultrapure water produced by a Milli-Q ultrapure water system (Millipore, US).

\subsection{SOS/umu assay}

To test the genotoxicity of quinolones, an ISO (International Organization for Standardization) recommended SOS/umu protocol (ISO13829) was performed (Oda et al., 1985; ISO, 2000). The engineered bacterium Salmonella thyphimurium TA1535/pSK1002 was provided from Professor Yoshimitsu Oda (Japan). In each test, 4-NQO (4-nitroquinoline-N-oxide) and culture medium were taken as positive control and negative control, respectively. For each quinolone, the lowest observed effective concentration (LOEC, M), at which induction ratio (IR) as 2 was determined. The toxicity test was conducted in triplicate, and the average of triplicate was used for reporting.

\subsection{D-QSAR method}

The ADRIANA.Code program (Ver. 2.2.4) was applied to calculate physicochemical parameters of the target molecules. The ADRIANA.Code is a program comprising a unique combination of methods for calculating molecular structure descriptors on a sound geometric and physicochemical basis. Totally, 29 global molecular descriptors, 8 shape descriptors and 88 2D property-weighted autocorrelation (or topological) descriptors were calculated. All calculated descriptors were selected as independent variables and $p L O E C(-\lg L O E C)$ as dependent variable. Stepwise multiple linear regression method was used to establish prediction models.

\subsection{D-QSAR method}

A 3D-QSAR model for genotoxicity of quinolones ( $p L O E C$ ) was constructed using comparative molecular field analysis (CoMFA) (Cramer et al., 1988). The 3D structures of all molecules were constructed using the standard tools available in SYBYL 7.0 molecular modeling package. Partial atomic charges were calculated using the Gasteiger-Hückel method. The energy minimization was performed using the Tripos force field with the Powell conjugate gradient algorithm and a convergence criterion of $0.005 \mathrm{kcal} / \mathrm{mol} \AA$. The compound CIP with an extensive commercial usage and lead role among quinolones was chosen as template molecule (Xu et al., 2002). The database alignment method was applied to superimpose all the compounds. A 3D view of aligned molecules based on CIP is shown in Supplementary material Fig. S1.

For CoMFA, the overlapped molecules were placed into a 3D cubic lattice with $2 \AA$ grid. A $\mathrm{sp}^{3}$ hybridized carbon atom with +1 charge served as the probe atom to generate steric and electrostatic field energy. A distance dependent dielectric constant of 1.0 was used. The default energy cutoff value was set at $30 \mathrm{kcal} /$ mol. The regression analysis was carried out using partial least square (PLS) method. The cross-validation with leave-one-out (LOO) method was carried out to yield the highest cross-validation correlation coefficient $\left(Q^{2}\right)$ and the optimum number of components $(N)$. At the same time, non-cross-validated analysis was performed, and the conventional multiple correlation coefficient $\left(R^{2}\right)$, standard error of estimate $(S E)$ and the Fisher test $(F)$ were calculated.

\section{Results and discussion}

\subsection{D-QSAR analysis}

It is reasonable to assume that the quinolone antibiotics take a similar interaction mechanism in inhibiting bacterial gyrase owing 
Table 1

Molecule structures of studied quinolones and transformation products.<smiles>CCN1C=C(C(=O)O)C(=O)c2cnc(N3CCNCC3)nc2N1CCCn1cc(C(=O)O)c(=O)c2cc(F)c(N3CCN(C)CC3)cc21</smiles>

Pefloxacin (PEF)<smiles>CCN1CCN(c2cc3c(cc2F)c(=O)c(C(=O)O)cn3C2CC2)CC1</smiles>

Enrofloxacin (ENR)<smiles>CN1CCN(c2c(F)cc3c(=O)c(C(=O)O)cn4c3c2SCC4)CC1</smiles>

Rufloxacin (RUF)<smiles>CC1CN(c2c(F)c(N)c3c(=O)c(C(=O)O)cn(C4CC4)c3c2F)CC(C)N1</smiles>

Sparfloxacin (SPA)<smiles>O=C(O)c1cn(-c2ccc(F)cc2)c2cc(N3CCNCC3)c(F)cc2c1=O</smiles>

Sarafloxacin (SAR)<smiles>CNc1cc2c(cc1F)c(=O)c(C(=O)O)cn2NC</smiles>

Amifloxacin (AMI)<smiles>CN1CCN(c2c(F)cc3c(=O)c(C(=O)O)cn4c3c2OCN4C)CC1</smiles>

Marbofloxacin (MAR)

c: Structures of 16 transformation products from CIP for genotoxicity estimation

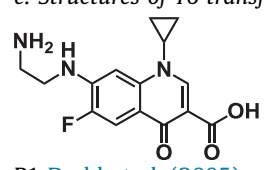

P1 Dodd et al. (2005);

De Witte et al. (2008)

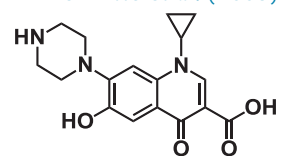

P5 Paul et al. (2010)

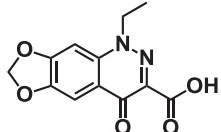

Cinoxacin (CIN)<smiles>CCn1cc(C(=O)O)c(=O)c2cc(F)c(N3CCNCC3)nc21</smiles>

Enoxacin (ENO)

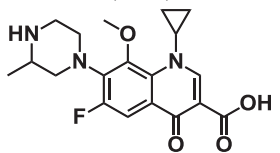

Gatifloxacin (GAT)

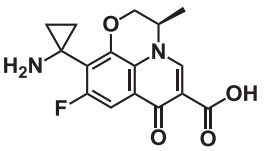

Pazufloxacin (PAZ)

NH

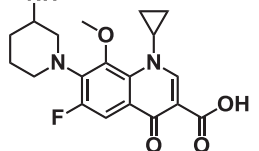

Balofloxacin (BAL)

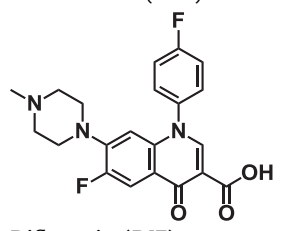

Difloxacin (DIF)

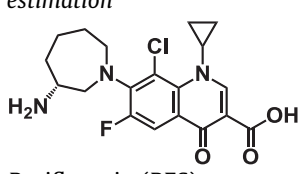

Besifloxacin (BES)

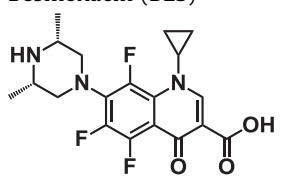

Orbifloxacin (ORB)

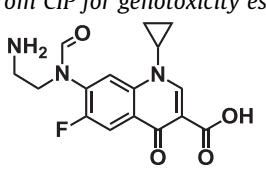

P2 Paul et al. (2010);

Sturini et al. (2012)

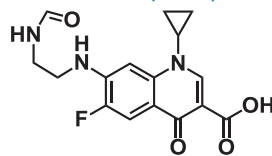

P6 Paul et al. (2010)<smiles>CCn1cc(C(=O)O)c(=O)c2cc(F)c(N3CCNCC3)cc21</smiles>

Norfloxacin (NOR)<smiles>O=C(O)c1cn(C2CC2)c2cc(N3CCNCC3)c(F)cc2c1=O</smiles>

Ciprofloxacin (CIP)<smiles>CC1COc2c(N3CCN(C)CC3)c(F)cc3c(=O)c(C(=O)O)cn1c23</smiles>

Ofloxacin (OFL)<smiles>CC1CCc2c(N3CCC(O)CC3)c(F)cc3c(=O)c(C(=O)O)cn1c23</smiles>

Nadifloxacin (NAD)<smiles>CN1CCN(c2c(F)cc3c(=O)c(C(=O)O)cn(CCF)c3c2F)CC1</smiles>

Fleroxacin (FLE)

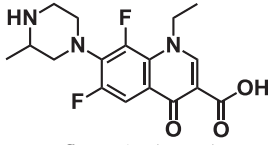

Lomefloxacin (LOM)<smiles>CN1CC2CC1CN2c1cc2c(cc1F)c(=O)c(C(=O)O)cn2C1CC1</smiles>

Danofloxacin (DAN)<smiles>CN1CCN(c2c(F)cc3c(=O)c(C(=O)O)cn4c3c2OCC4(C)C)CC1</smiles>

Levofloxacin (LEV)

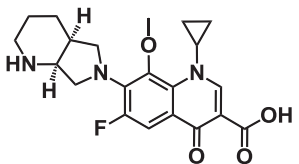

Moxifloxacin (MOX)

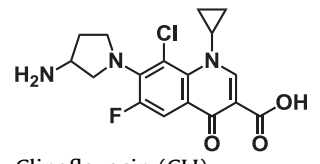

Clinafloxacin (CLI)<smiles>NC1CN(c2c(F)cc3c(=O)c(C(=O)O)cn(C4CC4F)c3c2Cl)CC12CC2</smiles>

Sitafloxacin (SIT)

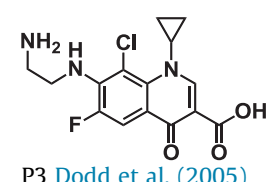

P3 Dodd et al. (2005

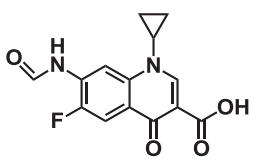

P7 Paul et al. (2010)<smiles></smiles>

Grepafloxacin (GRE)<smiles>CC1CN(c2cc3c(cc2F)c(=O)c(C(=O)O)cn3-c2ccc(F)cc2F)CCN1</smiles>

Temafloxacin (TEM)<smiles>Nc1cc2c(cc1F)c(=O)c(C(=O)O)cn2C1CC1</smiles>

P4 De Witte et al. 2008;

Paul et al. 2010

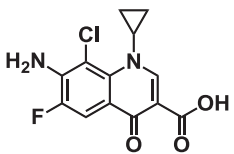

P8 Dodd et al. (2005) 
<smiles></smiles>

P9 Zhou et al. (2011)<smiles>O=C1CN(c2cc3c(cc2F)c(=O)c(C(=O)O)cn3C2CC2)CCN1</smiles>

P13 Sturini et al. (2012)

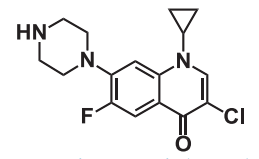

P10 Zhou et al. (2011)

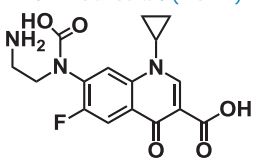

P14 Zhang and Huang (2005)

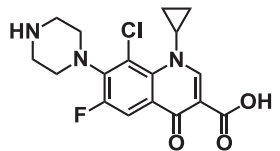

P11 Zhou et al. (2011) $\mathrm{HO}=\mathrm{O}$

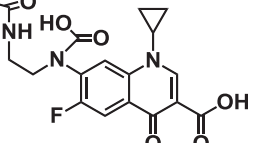

P15 Zhang and Huang (2005)

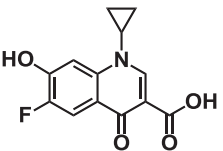

P12 Zhou et al. (2011)

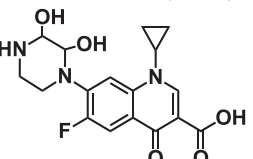

P16 Zhang and Huang (2005)

Table 2

The molecular structure descriptors and genotoxicity values ( $p L O E C, \mathrm{M}$ ) of 21 quinolones.

\begin{tabular}{|c|c|c|c|c|c|c|c|c|}
\hline \multirow[t]{2}{*}{ Comp. } & \multicolumn{6}{|l|}{ 2D-QSAR } & \multicolumn{2}{|l|}{ 3D-QSAR } \\
\hline & pLOEC (expt.) & 2DACorr_PiChg_2 & 2DACorr_LpEN_1 & Complexity & pLOEC (pred.) & Residual & pLOEC (pred.) & Residual \\
\hline BAL & 7.310 & -0.02663 & 132.346 & 667.836 & 7.956 & -0.646 & 7.300 & 0.010 \\
\hline CIP & 7.854 & -0.02537 & 114.065 & 571.428 & 7.795 & 0.059 & 7.846 & 0.008 \\
\hline DAN & 7.658 & -0.02553 & 112.963 & 663.952 & 8.463 & -0.805 & 7.632 & 0.026 \\
\hline DIF & 8.056 & -0.01063 & 148.543 & 672.082 & 8.299 & -0.244 & 8.124 & -0.069 \\
\hline ENR & 8.745 & -0.02537 & 114.396 & 613.151 & 8.079 & 0.666 & 8.744 & 0.001 \\
\hline FLE & 6.770 & -0.02629 & 153.684 & 595.047 & 6.929 & -0.159 & 6.753 & 0.017 \\
\hline GAT & 8.276 & -0.02663 & 132.469 & 652.866 & 7.848 & 0.427 & 8.267 & 0.009 \\
\hline LOM & 7.538 & -0.02624 & 136.276 & 585.485 & 7.299 & 0.239 & 7.582 & -0.044 \\
\hline MOX & 8.886 & -0.02663 & 132.426 & 726.715 & 8.366 & 0.520 & 8.869 & 0.017 \\
\hline NAD & 8.076 & -0.0252 & 120.475 & 631.029 & 8.059 & 0.017 & 8.042 & 0.034 \\
\hline OFL & 7.959 & -0.02673 & 131.433 & 633.926 & 7.737 & 0.222 & 7.985 & -0.026 \\
\hline PAZ & 8.538 & -0.02132 & 117.823 & 602.888 & 8.103 & 0.435 & 8.534 & 0.004 \\
\hline RUF & 6.886 & -0.02576 & 138.892 & 607.945 & 7.412 & -0.526 & 6.904 & -0.018 \\
\hline SAR & 7.921 & -0.01063 & 148.276 & 644.607 & 8.113 & -0.193 & 7.904 & 0.017 \\
\hline SPA & 7.367 & -0.03776 & 151.061 & 690.666 & 7.149 & 0.218 & 7.348 & 0.019 \\
\hline $\mathrm{LEV}^{\mathrm{a}}$ & 7.745 & -0.02673 & 131.433 & 633.926 & 7.737 & 0.008 & 7.975 & -0.230 \\
\hline $\mathrm{NOR}^{\mathrm{a}}$ & 7.672 & -0.02546 & 112.135 & 518.700 & 8.555 & -0.883 & 7.784 & -0.112 \\
\hline $\mathrm{PEF}^{\mathrm{a}}$ & 7.959 & -0.02546 & 112.402 & 545.199 & 7.649 & 0.310 & 7.682 & 0.277 \\
\hline $\mathrm{CIN}^{\mathrm{b}}$ & 6.523 & -0.02836 & 134.878 & 449.401 & 6.286 & 0.237 & & \\
\hline $\mathrm{ENO}^{\mathrm{b}}$ & 7.076 & -0.04235 & 116.224 & 520.851 & 6.625 & 0.451 & & \\
\hline $\mathrm{PIP}^{\mathrm{b}}$ & 4.798 & -0.08336 & 95.9007 & 488.870 & 5.069 & -0.271 & & \\
\hline
\end{tabular}

a Test set compounds to 3D-QSAR.

b Exclusive compounds to 3D-QSAR since their naphthyridone core.
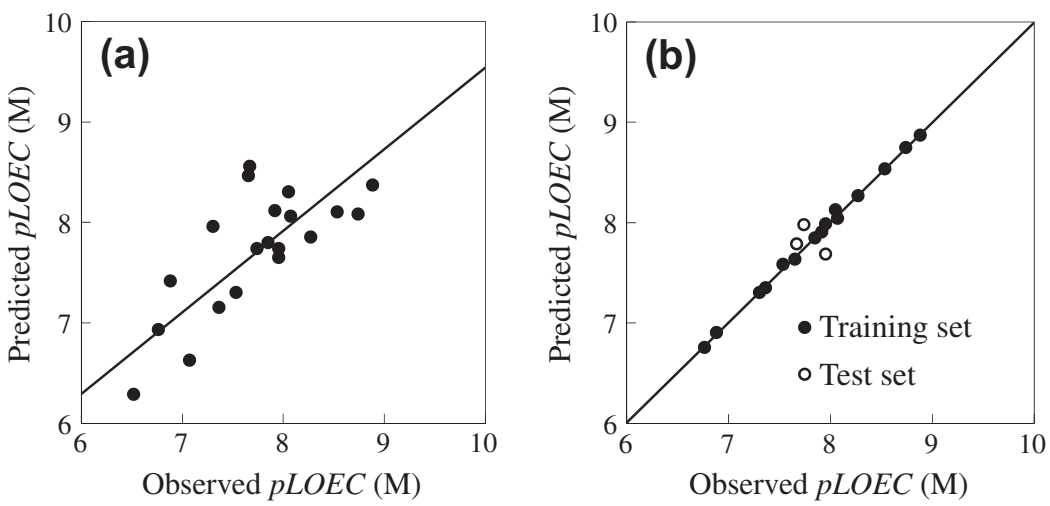

Fig. 1. The plot of observed $v s$ predicted pLOEC values using (a) 2D-QSAR model and (b) 3D-QSAR model, respectively.

to the structural common quinolone skeleton (see Fig. S2). The potency and spectrum of antibacterial activities were mainly dominated by the type of substituent and the substituted positions on quinolone framework. Therefore, quantitative structure-activity relationship (QSAR) technique can exert its advantages on discovering the dependence of genotoxicity on their molecular structures. A statistical model Eq. (1) between the genotoxicity ( $p L O E C)$ values (listed in Table 2) and physicochemical descriptors was developed by stepwise multiple linear regression analysis.
The plot of observed vs predicted pLOEC values is shown in Fig. 1a.

$$
\begin{aligned}
& \text { pLOEC }= 9.161( \pm 1.365)+49.342( \pm 8.620) \times 2 \text { DACorr_PiChg_2 } \\
&-0.028( \pm 0.008) \times 2 \text { DACorr_LpEN_1 }+0.006( \pm 0.002) \\
& \times \text { Complexity } \\
& N=21, R^{2}=0.777, R_{a d j}^{2}=0.738, S E=0.455, F=19.762, p<0.001
\end{aligned}
$$



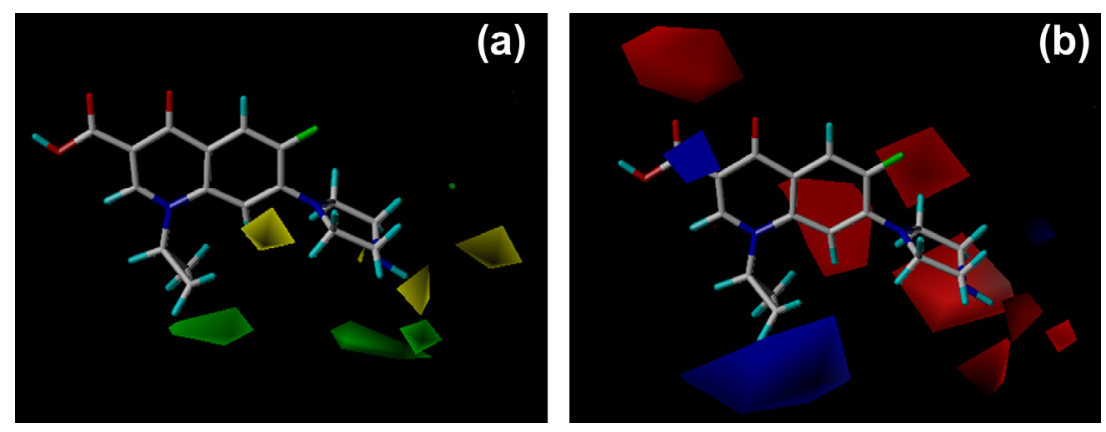

Fig. 2. The contour maps of CoMFA model, (a) steric field and (b) electrostatic field.

Three physicochemical descriptors (2DACorr_PiChg_2, 2DACorr_LpEN_1, Complexity) were involved in Eq. (1). Complexity is derived from the molecular topology (2D structure diagram) and is based on the atom connectivity as well as symmetry in a molecule (Hendrickson et al., 1987). 2DACorr_PiChg_2 is the second component of $2 \mathrm{D}$ autocorrelation coefficients for $\pi$ charges, where the distance $d=1$. 2DACorr_LpEN_1 is the first component of 2D autocorrelation coefficient for lone pair electron negativities, where the distance $d=0$ (Wang et al., 2012). The detailed calculation methods for 2DACorr_PiChg_2 and 2DACorr_LpEN_1 are provided in the Text S1.

As shown in Eq. (1), the genotoxicity of quinolones was dependent on the molecular properties of electronegativity ( $\pi$ charges and lone pair electron negativities) and steric parameter (Complexity). Indeed, structure analoge of 2-benzoylacrylic in quinolone molecule consists a big conjugated system containing 12 of $\pi$ electrons. $\mathrm{C}$ atoms and heteroatoms $\mathrm{F}, \mathrm{N}$ and $\mathrm{O}$ provide lone pair electrons. This study is consistent with a previous study stating that the electron transfer may occur when quinolone interacts with DNA or protein (Hu et al., 2007). The 2D-QSAR model indicated that electronegativity and steric parameter had good correlation with the genotoxicity of quinolones. However, it is not clear regarding which substitution position and what kind of substituent could provide the most significant contribution to the genotoxicity. A 3D-QSAR (CoMFA) study was then conducted to obtain more comprehensive information.

\subsection{D-QSAR analysis}

\subsubsection{D-QSAR model}

A 3D-QSAR model for 15 randomly selected quinolones as a training set was established by CoMFA method, which indicated that the contribution of steric and electrostatic field was $77.0 \%$ and $23.0 \%$, respectively. The developed 3D-QSAR model involving 5 optimum components which exhibits high correlation $\left(R^{2}=0.998, Q^{2}=0.562\right)$ and significance $\left(Q^{2}\right.$ should be more than 0.5 ). The $F$ value and $S E$ value of the model are 125.019 and 0.035 , respectively. The plot of observed $v s$ predicted $p L O E C$ values is shown in Fig. 1b.

In order to check the predictability of the developed CoMFA model, the genotoxicity of three randomly selected quinolones (LEV, NOR and PEF) were taken as test set. It was found that the predicted PLOEC values were in good agreement with their experimental results, and the predictive correlation coefficient $R_{\text {pred. }}^{2}$ (calculated with the method described in Text S2) was 0.974. These results indicate that the established CoMFA model is reliable and predictive.

\subsubsection{D-QSAR contour maps analyses}

The contour maps from the CoMFA model are shown in Fig. 2, and the template compound CIP was displayed in the background as well. It was expected that the contribution of substitution position and substituent property on the genotoxicity could be comprehensively disclosed by analyzing the color, size and covering region of contour maps.

To the steric contour map ${ }^{1}$ (Fig. 2a), the green and yellow contours respectively take $80 \%$ and $20 \%$ of contribution. The green contours represent that steric bulk is favorable for increasing genotoxicity, whereas the yellow contours represent that the steric bulk leads to decrease genotoxicity. In Fig. 2a, two big green contours appear at 1 - and 7-positions, which mean that introducing bulky groups into these two positions could increase the genotoxicity. This point can be supported by comparing the genotoxicity of some quinolones analoges with different volume of substituents at 1- or 7-positions. The substituents at 1-position of NOR, CIP and SAR were ethyl, cyclopropyl and 4-fluorophenyl, respectively. It was noted that genotoxicity increased with increasing substituent volume. The substituents at 7-position were either piperazine or bigger N-methylated piperazine in three groups NOR and PEF, CIP and ENR, SAR and DIF, the quinolones with N-methylated piperazine exhibited relatively high genotoxicity. MOX, with a notable bulky substituent at 7-position, presented higher genotoxicity comparing to GAT and BAL. However, the observation of inconsiderable two small yellow contours near 7-position of quinolone ring indicated that the small substituent also preferred to increase toxicity. This result was supported by the stronger toxicity of PAZ with a very small cyclopropylamine than that of LEV with N-methylated piperazine at 7-position. Besides, another small yellow contour near 8-position suggested that substituent with small volume at this position could increase genotoxicity. On the whole, the steric effect contributed $77 \%$ to the genotoxicity of quinolones, and the tested quinolones containing bulky and more substituents, such as DIF, MOX and SPA, usually exhibited relatively high genotoxicity. This is correlated with the positive contribution of descriptor Complexity in the 2D-QSAR model.

To the electrostatic contour map (Fig. 2b), the red and blue contours contributed $80 \%$ and $20 \%$, respectively. The red contours indicated regions where negative charge increased the genotoxicity, while the blue contours indicated regions where positive charge improved the genotoxicity. There were two big red contours around at 3- and 6-positions, which indicated that the substituents with negative charge on these positions could increase the genotoxicity. In fact, the carboxyl group at 3-position and $\mathrm{F}$ atom at 6-position have been optimized well for antibacterial activity and high potency during drug design (Domagala, 1994). Another two big red contours covered at 7- and 8-positions. At 7-position, the most common substituents are nitrogen heterocycles in which $\mathrm{N}$ atom has high electronegativity. Similarly, the substituent at 8position with negative charge is favorable for high toxicity. For

\footnotetext{
${ }^{1}$ For interpretation of color in Fig. 2, the reader is referred to the web version of this article.
} 
Table 3

The estimated genotoxicity values ( $p L O E C, \mathrm{M}$ ) of 8 quinolones and 16 transformation products.

\begin{tabular}{|c|c|c|c|c|c|}
\hline \multicolumn{2}{|c|}{ Quinolone precursors } & \multicolumn{4}{|c|}{ Transformation products of CIP } \\
\hline Comp. & pLOEC & No. & pLOEC & No. & pLOEC \\
\hline AMI & 8.00 & P1 & 8.68 & P9 & 7.47 \\
\hline BES & 7.50 & $\mathrm{P} 2$ & 8.31 & P10 & 8.38 \\
\hline CLI & 7.19 & P3 & 7.38 & P11 & 7.40 \\
\hline GRE & 7.47 & P4 & 7.58 & P12 & 8.63 \\
\hline MAR & 8.46 & P5 & 8.49 & P13 & 7.87 \\
\hline ORB & 7.51 & P6 & 8.17 & P14 & 8.41 \\
\hline SIT & 7.28 & P7 & 7.52 & P15 & 8.30 \\
\hline TEM & 8.47 & P8 & 7.59 & P16 & 8.46 \\
\hline
\end{tabular}

example, GAT (with COMe at 8-position) exhibited higher genotoxicity than CIP (with $\mathrm{CH}$ at 8-position). Additionally, the decreasing toxicity of LOM, ENO and NOR could also be attributed to their decreasing electronegativity of groups $(\mathrm{CF}, \mathrm{CN}$ and $\mathrm{CH}$ ) at 8-position. A major blue region near 1-position indicated that the substituent with positive charge could increase the genotoxicity.

Although the specific contribution of each substituent to genotoxicity was discussed separately, the genotoxicity comes from an integral contribution from all substitutes in the molecule. Took FLE with low toxicity as an example, - CF at 8-position and N-methylated piperazine at 7-position were favorable for increasing genotoxicity, while the $-\mathrm{C}_{2} \mathrm{H}_{4} \mathrm{~F}$ at 1-position gave a negative contribution to genotoxicity. Additionally, a blue area in the steric map and green area in the electrostatic map covered at 1-position simultaneously, which inferred that bulk groups and positive charge at 1-position were favorable for high genotoxicity. This was evidenced by the higher genotoxicity of CIP and SAR than that of NOR.

Besides genotoxicity, some other toxicity effects of quinolones were tested with aquatic species as well, e.g., cyanobacterium (Microcystis aeruginosa, with $\mathrm{EC}_{50}$ value of $0.02-7.5 \mu \mathrm{M}$ for 7 tested quinolones), duckweed (Lemna minor, with $\mathrm{EC}_{50}$ value of $0.14-$ $0.3 \mu \mathrm{M}$ for 3 tested quinolones) (Migliore et al., 1997; Robinson et al., 2005; Yang et al., 2008; Ebert et al., 2011). It can be concluded that genotoxicity is much notable (with LOEC value of $1.3-15920 \mathrm{nM}$ for 21 tested quinolones in current study) than some other toxicity effects. Additionally, a good molecule structure - toxicity relationship was obtained in current study, while the contribution of chemical substituents to genotoxicity was not suitable for other toxicities. The differences between genotoxicity and the other toxicities may be ascribed to the different action mechanisms. Therefore, it is reasonable to infer that the genotoxicity feature of quinolones antibiotics should be one of the particular concerns for evaluating their potential environmental risk.

\subsection{Genotoxicity estimation of quinolones analoges}

\subsubsection{Estimation of genotoxicity for 8 quinolones}

In order to evaluate the potential healthy risk of some other quinolones antibiotics, the genotoxicity of 8 quinolones (Table 1b) was estimated using the developed 3D-QSAR model (Table 3). It could be seen that all of the estimated compounds showed high genotoxicity and the relationship of structure-genotoxicity could be explained by the 3D-QSAR model. For example, TEM with bulky substituents at 1- and 7-positions exhibited higher genotoxicity than SAR.

3.3.2. Estimation of genotoxicity for transformation products from CIP

CIP is a widely used quinolone drug, and its high residue in multiple environmental media has been reported. Correspondingly, its transformation characteristics during various artificial or natural processes, such as ozonation (De Witte et al., 2008), photolysis and photocatalysis (both under laboratory and natural sunlight) (Paul et al., 2010; Sturini et al., 2012), chlorination disinfection (Dodd et al., 2005; Zhou et al., 2011), manganese oxide (Zhang and Huang, 2005), were extensively explored. It was found that the transformation reactions of CIP mainly occurred at the substituents while the quinolone skeleton remained intact. However, less attention has been paid to the potential risk during the transformation processes and the toxicity of transformation products. A total of 16 transformation products from CIP were collected in Table 1c, and their estimated genotoxicity using the developed 3D-QSAR model were listed in Table 3. P1 is a common product from partial dealkylation on piperazine ring during ozonation, chlorination and manganese dioxide oxidation processes. Although the volume of half-piperazine ring was smaller than full-piperazine ring, two amine groups ( $\mathrm{R}-\mathrm{NH}-\mathrm{C}_{2} \mathrm{H}_{4}-\mathrm{NH}_{2}$ ) were bared which would withdraw more electronic cloud and increase negative charge at 7-position due to the high electro-negativity of $\mathrm{N}$ atoms. So the estimated result suggested that P1 showed higher toxicity than CIP. P4 is a product from a thorough dealkylation as $\mathrm{R}^{-\mathrm{NH}_{2}}$. The amine group directly binds to phenyl ring, it would donate electrons to phenyl ring and exhibit partial positive charge at 7-position, which would reduce its genotoxicity accompanying with the small volume. P16 showed higher genotoxicity than CIP, because two of exotic hydroxyls on piperazine ring not only increased the volume but also withdrawn more negative charges at 7-position. These results are in accordance with the CoMFA contour maps.

Overall, on basis of 3D-QSAR model estimation, most of examined CIP transformation products (10 out of 16) exhibited stronger genotoxicity than their parent CIP. This result provides a positive evidence for the increasing toxicity in photolysis or chlorination processes of antibiotics (Jiao et al., 2008; Li et al., 2011). Consequently, the toxicity elevation after disinfection process of pharmaceuticals should be of concerns as well.

\section{Conclusions}

The genotoxicity of 21 quinolones antibiotics was studied based on SOS/umu testing and 2D- and 3D-QSAR modeling. The results suggested that the steric and electrostatic properties of substituents had significant correlation with genotoxicity. It was found that, the substituent with bigger volume and/or positive charge at 1-position, with smaller volume and/or negative charge at 8-position, and with negative charge at 7-position could be favorable for genotoxicity augment. The developed CoMFA model has excellent significance, robustness and predictability, so that it can be used to estimate genotoxicity for other quinolones antibiotics and transformation products. It is interesting to notice that some of the transformation products exhibit higher genotoxicity than their precursor. The current study could be applied to screen the potential environmental risks of quinolones antibiotics.

\section{Acknowledgements}

This work was supported in partial by the National Natural Science Foundation of China (Projects 20890112, 50938004, and 20877090). The authors thank Prof. Aixia Yan and Mr. Jiaxuan Li for their help in 2D-QSAR modeling.

\section{Appendix A. Supplementary material}

Supplementary data associated with this article can be found, in the online version, at http://dx.doi.org/10.1016/j.chemosphere. 2013.09.002. 


\section{References}

Andersson, M.I., Mac Gowan, A.P., 2003. Development of the quinolones. J. Antimicrob. Chemother. 51, 1-11.

Blum, D.J.W., Speece, R.E., 1990. Determining chemical toxicity to aquatic species. Environ. Sci. Technol. 24, 284-293.

Bryan, L.E., Bedard, J., Wong, S., Chamberland, S., 1989. Quinolone antimicrobial agents: mechanism of action and resistance development. Clin. Invest. Med. 12 (1), 14-19.

Cramer, R.D., Patterson, D.E., Bunce, J.D., 1988. Comparative molecular-field analysis (CoMFA) 1. Effect of shape on binding of steroids to carrier proteins. J. Am. Chem. Soc. 110, 5959-5967.

De Witte, B., Dewulf, J., Demeestere, K., De Vyvere, V.V., De Wispelaere, P., Van Langenhove, H., 2008. Ozonation of ciprofloxacin in water: HRMS identification of reaction products and pathways. Environ. Sci. Technol. 42, 4889-4895.

De Witte, B., Van Langenhove, H., Hemelsoet, K., Demeestere, K., De Wispelaere, P., Van Speybroeck, V., Dewulf, J., 2009. Levofloxacin ozonation in water: rate determining process parameters and reaction pathway elucidation. Chemosphere 76, 683-689.

Dodd, M.C., Shah, A.D., Von Gunten, U., Huang, C.H., 2005. Interactions of fluoroquinolone antibacterial agents with aqueous chlorine: reaction kinetics, mechanisms, and transformation pathways. Environ. Sci. Technol. 39, 70657076.

Domagala, J.M., 1994. Structure-activity and structure-side-effect relationships for the quinolone antibacterials. J. Antimicrob. Chemother. 33, 685-706.

Ebert, I., Bachmann, J., Kuhnen, U., Kuster, A., Kussatz, C., Maletzki, D., Schluter, C., 2011. Toxicity of the fluoroquinolone antibiotics enrofloxacin and ciprofloxacin to photoautotrophic aquatic organisms. Environ. Toxicol. Chem. 30, 2786-2792.

Ge, L.K., Chen, J.W., Wei, X.X., Zhang, S.Y., Qiao, X.L., Cai, X.Y., Xie, Q., 2010. Aquatic photochemistry of fluoroquinolone antibiotics: kinetics, pathways, and multivariate effects of main water constituents. Environ. Sci. Technol. 44, 2400-2405.

Golet, E.M., Alder, A.C., Giger, W., 2002. Environmental exposure and risk assessment of fluoroquinolone antibacterial agents in wastewater and river water of the Glatt valley watershed, Switzerland. Environ. Sci. Technol. 36, 3645-3651.

Hartmann, A., Alder, A.C., Koller, T., Widmer, R.M., 1998. Identification of fluoroquinolone antibiotics as the main source of umuC genotoxicity in native hospital wastewater. Environ. Toxicol. Chem. 17, 377-382.

Hendrickson, J.B., Huang, P., Toczko, A.G., 1987. Molecular complexity - a simplified formula adapted to individual atoms. J. Chem. Inf. Comput. Sci. 27, 63-67.

Hirsch, R., Ternes, T., Haberer, K., Kratz, K.L., 1999. Occurrence of antibiotics in the aquatic environment. Sci. Total Environ. 225, 109-118.

Hooper, D.C., 2001. Mechanisms of action of antimicrobials: focus on fluoroquinolones. Clin. Infect. Dis. 32, S9-S15.

Hu, J.Y., Wan, W.F., Zhu, Z., Chang, H., Pan, F., Lin, B., 2007. Quantitative structureactivity relationship model for prediction of genotoxic potential for quinolone antibacterials. Environ. Sci. Technol. 41, 4806-4812.

ISO, 2000. Water Quality - Determination of the Genotoxicity of Water and Waste Water Using the umu-test, first ed. ISO 13829, Geneva, Switzerland, pp. 1-18.

Jia, A., Wan, Y., Xiao, Y., Hu, J.Y., 2012. Occurrence and fate of quinolone and fluoroquinolone antibiotics in a municipal sewage treatment plant. Water Res. 46, 387-394.

Jiao, S.J., Zheng, S.R., Yin, D.Q., Wang, L.H., Chen, L.Y., 2008. Aqueous photolysis of tetracycline and toxicity of photolytic products to luminescent bacteria. Chemsphere 73, 377-382.

Lee, K.W., Kwon, S.Y., Hwang, S., Lee, J.U., Kim, H.J., 1996. Quantitative structureactivity relationships (QSAR) study on C-7 substituted quinolone. Bull. Korean Chem. Soc. 17, 147-152.

Li, Y., Niu, J.F., Wang, W.L., 2011. Photolysis of enrofloxacin in aqueous systems under simulated sunlight irradiation: kinetics, mechanism and toxicity of photolysis products. Chemosphere $85,892-897$.
Lindberg, R., Jarnheimer, P.A., Olsen, B., Johansson, M., Tysklind, M., 2004 Determination of antibiotic substances in hospital sewage water using solid phase extraction and liquid chromatography/mass spectrometry and group analogue internal standards. Chemosphere 57, 1479-1488.

Llorente, B., Leclerc, F., Cedergren, R., 1996. Using SAR and QSAR analysis to model the activity and structure of the quinolone-DNA complex. Bioorg. Med. Chem. 4, $61-71$.

Mamber, S.W., Kolek, B., Brookshire, K.W., Bonner, D.P., Fungtomc, J., 1993. Activity of quinolones in the Ames Salmonella-TA102 mutagenicity test and other bacterial genotoxicity assays. Antimicro. Agents Chem. 37, 213-217.

Martins, A.F., Vasconcelos, T.G., Henriques, D.M., Frank, C.D., Konig, A., Kummerer K., 2008. Concentration of ciprofloxacin in Brazilian hospital effluent and preliminary risk assessment: a case study. Clean - Soil Air Water 36, 264-269.

Migliore, L., Civitareale, C., Brambilla, G., DiDelupis, G.D., 1997. Toxicity of severa important agricultural antibiotics to Artemia. Water Res. 31, 1801-1806.

Minovski, N., Vracko, M., Solmajer, T., 2011. Quantitative structure-activity relationship study of antitubercular fluoroquinolones. Mol. Diversity 15, 417426.

Oda, Y., Nakamura, S., Oki, I., Kato, T., Shinagawa, H., 1985. Evaluation of the new system (umu-test) for the detection of environmental mutagens and carcinogens. Mutat. Res. 147, 219-229.

Ohta, M., Koga, H., 1991. 3-dimensional structure-activity-relationships and receptor mapping of $\mathrm{N} 1$-substituents of quinolone antibacterials. J. Med. Chem. 34, 131-139.

Paul, T., Dodd, M.C., Strathmann, T.J., 2010. Photolytic and photocatalytic decomposition of aqueous ciprofloxacin: transformation products and residual antibacterial activity. Water Res. 44, 3121-3132.

Robinson, A.A., Belden, J.B., Lydy, M.J., 2005. Toxicity of fluoroquinolone antibiotics to aquatic organisms. Environ. Toxicol. Chem. 24, 423-430.

Sturini, M., Speltini, A., Maraschi, F., Profumo, A., Pretali, L., Irastorza, E.A., Fasani, E. Albini, A., 2012. Photolytic and photocatalytic degradation of fluoroquinolones in untreated river water under natural sunlight. Appl. Catal. B - Environ. 119 32-39.

Tong, C.L., Zhuo, X.J., Guo, Y., 2011. Occurrence and risk assessment of four typical fluoroquinolone antibiotics in raw and treated sewage and in receiving waters in Hangzhou, China. J. Agric. Food Chem. 59, 7303-7309.

Wang, M.L., Wang, K., Yan, A.X., Yu, C.Y., 2012. Classification of HCV NS5B polymerase inhibitors using support vector machine. Int. J. Mol. Sci. 13, 4033-4047.

Wei, R.C., Ge, F., Chen, M., Wang, R., 2012. Occurrence of ciprofloxacin, enrofloxacin, and florfenicol in animal wastewater and water resources. J. Environ. Qual. 41, $1481-1486$.

Wetzstein, H.G., Stadler, M., Tichy, H.V., Dalhoff, A., Karl, W., 1999. Degradation of ciprofloxacin by basidiomycetes and identification of metabolites generated by the brown rot fungus Gloeophyllum striatum. Appl. Environ. Microbiol. 65 (4), 1556-1563.

Xu, M., Zhang, A.Q., Han, S.K., Wang, L.S., 2002. Studies of 3D-quantitative structureactivity relationships on a set of nitroaromatic compounds: CoMFA, advanced CoMFA and CoMSIA. Chemsphere 48, 707-715.

Yang, L.H., Ying, G.G., Staubner, J.L., Adams, M.S., Binet, M.T., 2008. Growthinhibiting effects of 12 antibacterial agents and their mixtures on the freshwater microalga Pseudokirchneriella subcapitata. Environ. Toxicol. Chem. 27, 1201-1208.

Zhang, H.C., Huang, C.H., 2005. Oxidative transformation of fluoroquinolone antibacterial agents and structurally related amines by manganese oxide. Environ. Sci. Technol. 39, 4474-4483.

Zhou, H., Ouyang, Q., Peng, M., Li, W., 2011. Investigation on the reaction of ciprofloxacin and chlorine. J. Sun Yatsen Univ. (Nat. Sci. Ed.) 50, 79-84 (in Chinese). 